\title{
Passive anti-amyloid immunotherapy in Alzheimer's disease: What are the most promising targets?
}

\author{
Jens Moreth, Chrystelle Mavoungou and Katharina Schindowski
}

\begin{abstract}
Alzheimer's disease (AD) is the most common dementia in the industrialized world, with prevalence rates well over $30 \%$ in the over 80 -years-old population. The dementia causes enormous costs to the social healthcare systems, as well as personal tragedies for the patients, families and caregivers. AD is strongly associated with Amyloid-beta (A $\beta$ ) protein aggregation, which results in extracellular plaques in the brain, and according to the amyloid cascade hypothesis appeared to be a promising target for the development of $A D$ therapeutics. Within the past decade convincing data has arisen positioning the soluble prefibrillar $A \beta$-aggregates as the prime toxic agents in AD. However, different $A \beta$ aggregate species are described but their remarkable metastability hampers the identification of a target species for immunization. Passive immunotherapy with monoclonal antibodies (mAbs) against $A \beta$ is in late clinical development but recently the two most advanced mAbs, Bapineuzumab and Solanezumab, targeting an N-terminal or central epitope, respectively, failed to meet their target of improving or stabilizing cognition and function. Preliminary data from off-label treatment of a small cohort for 3 years with intravenous polyclonal immunoglobulins (IVIG) that appear to target different conformational epitopes indicate a cognitive stabilization. Thus, it might be the more promising strategy reducing the whole spectrum of A $\beta$-aggregates than to focus on a single aggregate species for immunization.
\end{abstract}

Keywords: Passive immunization, Dementia, Therapeutic antibodies, Effector function, Oligomers, ADDLs, Protofibrils, Regulatory strategy

\section{$A ß$-aggregates and their impact in choosing the right antibody}

Alzheimer's disease (AD) is the most common form of dementia. It accounts for $60-70 \%$ of all cases among the oldest old [1]; and countries in demographic transition will experience the greatest growth. $\mathrm{AD}$ is a multifactorial disease with pathogenic cerebral protein aggregation, including aggregation of hyperphosphorylated tau (phospho-tau) and the aggregation and deposition of Amyloid- $\beta(A \beta)$, accompanied by oxidative stress and glial activation [2]. Thus, many pathophysiological pathways coexist, resulting in synaptic dysfunction and severe neuronal loss that cause deterioration and finally loss of memory and cognition. Within the past two decades substantial efforts have been made to elucidate the toxic nature of $\mathrm{A} \beta$ in $\mathrm{AD}$. The

\footnotetext{
* Correspondence: zimmermann@hochschule-bc.de

Institute of Applied Biotechnology, Faculty for Biotechnology, Biberach

University of Applied Science, Karlstrasse 11, Biberach/Riss D-88400, Germany
}

primary event that induces the abnormal accumulation of $A \beta$ is the dysregulated proteolytic processing by secretases of its parent molecule, the amyloid precursor protein (APP) [3]. Dysregulated APP-processing results in the A $\beta$ peptide of predominantly 39 to 43 residues, but even smaller species occur. Further post-translational modifications result in a various number of $\mathrm{N}$ - and $\mathrm{C}$-terminal variants of the $\mathrm{A} \beta$-peptide [4], increasing heterogeneity and, thus, the number of possible targets.

The aggregation of $A \beta$ species is thought to play a pivotal role in the disease progression of $\mathrm{AD}$ through a cascade of events, called the amyloid cascade hypothesis [5-7]. In the light of the recent clinical trials with anti$\mathrm{A} \beta$ drugs the amyloid cascade hypothesis is again a subject of discussion.

The self-association of $\mathrm{A} \beta$-peptide results in aggregates with varying morphology and molecular weight

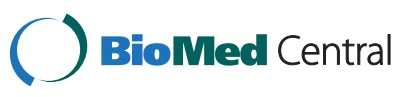




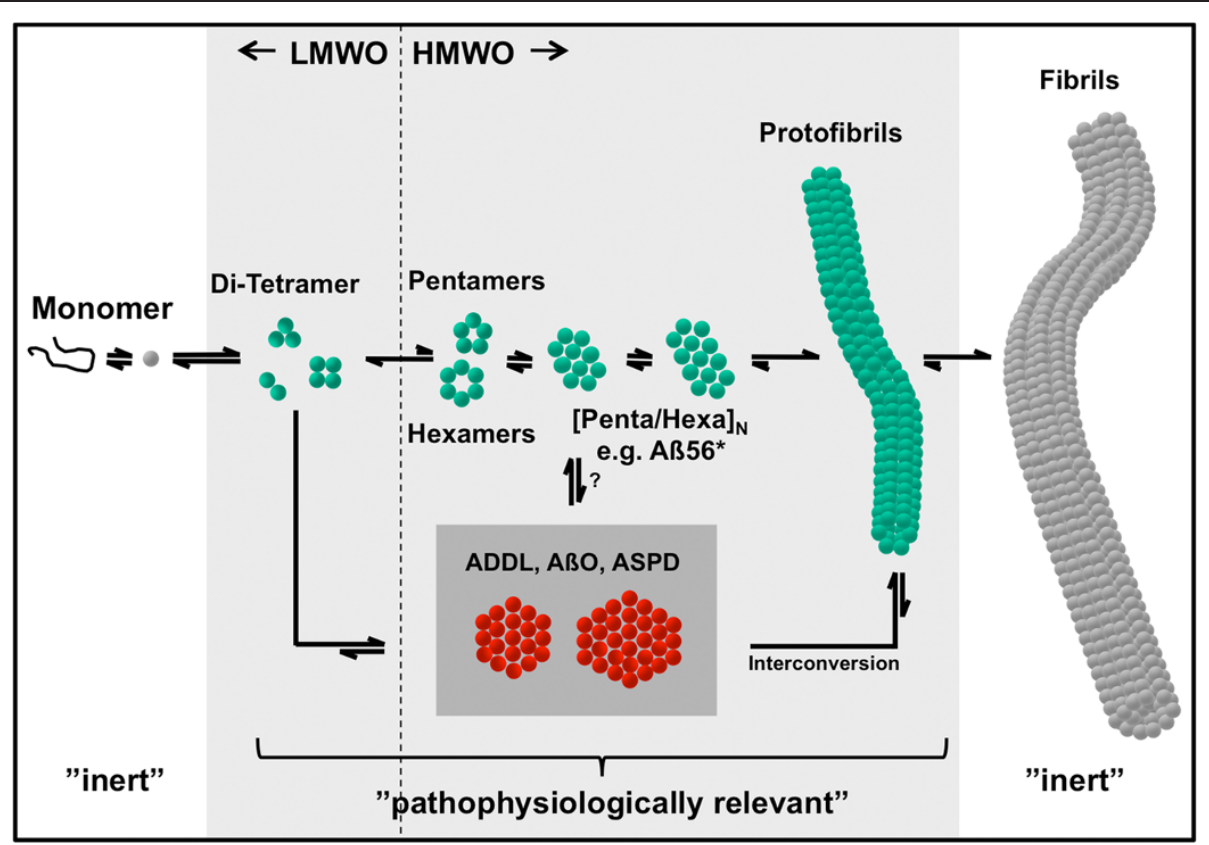

Figure 1 Pathways of aggregation and observed Aß-aggregate intermediates. Monomeric Aß folds to the activated state and then exists in rapid equilibrium with low molecular weight oligomers, which aggregate over various transient high molecular weight intermediates to matured fibrils. The definition of LMW and HMW oligomers is related to the elution profile of Aß-aggregates in size exclusion chromatography, revealing two predominant peaks at the exclusion limit $(>60 \mathrm{kDa})$ and at the void volume $(4-20 \mathrm{kDa})$, respectively. The HMW intermediates comprise pentamers, hexamers and multiples thereof, finally forming protofibrils, which are the precursors for multi-stranded ribbons of matured fibrils. Further neurotoxic aggregate species e.g. ABO, ADDL and ASPD are believed to aggregate over alternative pathways but preliminary data revealed that these are able to converge into the other pathways of aggregation (inter-conversion). Interestingly, every change in the experimental paradigm can provoke this aggregate conversion. Therefore, one might assume that many different aggregates coexist and, thus, neurotoxicity can be attributed to several pathogenic modes of action. Monomers and fibrils are believed to be biologically inert; however fibrils are able to collapse into protofibrils and then also reveal toxicity. The broad range of prefibrillar aggregates have been reported as pathophysiologically relevant in AD.

$A \beta$-peptide subsequent to secretase cleavage $A ß$ folds to an activated monomeric state and then exists in rapid equilibrium with low molecular weight aggregates [8]. These further associate over various transient intermediates to mature insoluble $A \beta$-fibrils, which accumulate in the AD brain as senile plaques. Further investigations focused on the prefibrillar aggregates, the water-soluble oligomers, which are increased in AD-patients [9]. However, the term "soluble" roughly describes aggregates, which remain in solution upon centrifugation at $15000 \times$ $g$ [10]. Monomeric and fibrillar $A \beta$ are believed to be biologically inert; however $A ß$-fibrils can collapse back into protofibrils in the presence of lipids and then also reveal toxicity [11]. The oligomeric species show, so far, the best correlation to neuro-psychiatric analysis and synapse loss [12-14]. These results increased the impact of soluble, premature $A \beta$-aggregates in the disease progression of $\mathrm{AD}$, which has been positioned in the reformulated amyloid cascade hypothesis by Selkoe and Walsh [15]. Huge efforts have been made to identify distinct $A \beta$-aggregates derived from synthetic peptide and natural sources, resulting in a plethora of described $A \beta-$ species with overlapping size and morphology [16]: the A $\beta$-dimer $[17,18]$, low-molecular weight oligomers, comprising dimeric to tetrameric $A ß$ [19], pentamers and hexamers [20], the dodecameric Aß56* derived from transgenic mice and human brain [21,22], globulomers [23], Aß-oligomers [24], Alzheimer-derived diffusible ligands - ADDL [10], protofibrils [25], amylospheroids [26] just to mention the major $A \beta$-preparations in the field. $A$ further complexity comes with the various $A \beta$-fragments including the $\mathrm{N}$ - and $\mathrm{C}$-terminal truncated $\mathrm{A} \beta$-species.

Some of these different $A \beta$-preparations have been used for immunization and screening to generate therapeutic monoclonal antibodies (mAbs) which are being evaluated in preclinical and clinical trials. Literally, the definitions for all the above-mentioned $A \beta$-aggregate species are based on the protocols for $A \beta$-aggregate preparation and the methods used for characterization. These definitions are not strictly used - resulting in controversy regarding the reported $\mathrm{A} \beta$-species and the observed patho-physiological effects. It still remains unsolved whether the reported synthetic $A \beta$-aggregates exist in vivo since they are hardly comparable to the 
naturally derived $A \beta$-species. Synthetic $A \beta$ allows for indepth biophysical characterization based on high protein concentrations and purity however these $A \beta$-aggregates have to be critically reviewed since high protein concentrations are necessary for their generation. Intriguingly, endogenous $A \beta$ reveals nanomolar concentrations in the brain and comprises a heterogeneous peptide-mixture with post-translational modifications and truncations at the $\mathrm{N}$ - and $\mathrm{C}$-terminus, respectively. Furthermore, the characterization of natural derived $A \beta$, e.g. from tissue, CSF or blood, needs sophisticated methods for extraction which have an intrinsic effect on the identity of the $\mathrm{A} \beta$-species and thus eludes a characterization of the aggregates originally present under native conditions. The common methods used for characterization of endogenous A $\beta$, e.g. SDS-PAGE, do not resolve the actual aggregative state. Thus, despite the reported presence of prefibrillar $A \beta$ [27] the debate about the most relevant $A \beta$-species is still controversial. The identification of endogenous $A \beta$-aggregates is hampered owing to the dynamic and non-linear nature of aggregation and methodological limitations [28-30]. To this date the larger aggregates (e.g. ADDL, $\mathrm{A} \beta \mathrm{O}$ ) could not be shown in vivo by means of biophysics to structurally relate them to endogenous $A \beta$. Moreover, owing to the metastability and the ability for inter-conversion of different aggregation pathways, it is questionable whether to focus on a single "most-toxic" $A \beta$-species rather than the whole spectrum of $A \beta$-aggregates [28]. With regard to an anti-A $\beta$ therapy, depleting total $A \beta$ including all various $A \beta$ fragments and aggregative species might be favorable compared to one conformation or speciesspecific antibodies since these might pick only one rogue out of many.

\section{$A \beta$ immunotherapy with monoclonal antibodies}

Although AD has been known about for over 100 years, there is still only symptomatic treatment available on the market. According to the amyloid cascade hypothesis, eradication of $A \beta$ appears to be the aim for any diseasemodifying therapy against $\mathrm{AD}$, a therapy that is desperately needed to deal with the millions of $\mathrm{AD}$ patients in the upcoming decades.

The first active immunotherapy trial (AN-1792) using aggregated, full-length $A \beta_{42}$ was halted after $6 \%$ of the patients developed severe meningoencephalitis [31]. The active vaccination with $A \beta_{42}$ and adjuvant produced both a humoral and a cellular response against $A \beta$ resulting in a strong and in some cases fatal immune response against the endogenous peptide $A \beta$ [32].

Consequently, passive immunization as alternative was considered safer and more controllable than active immunization (see Table 1 for current trials). The mechanism of action of mAbs is firstly the capture of the target and secondly the effector function linked to the Fc domain of the mAb (for review see [33]). But how can antibodies against $A \beta$ interfere with $A D$ pathology? Despite the rapid advance of this therapeutic strategy into clinical trials and the hundreds of research papers, there still remain enigmatic aspects in $A \beta$ immunotherapy [2]. Most importantly the mechanism of action is still not elucidated in rodents, let alone in humans, although many hypotheses have been proposed - including microglia-mediated phagocytosis, antibody-mediated alterations of $A \beta$ aggregation and neutralization of $A \beta$ toxicity, intracerebral sequestration of $A \beta$ in a monomeric state and peripheral sink [34].

Besides the microglial engulfment of $A \beta$, the other discussed mechanisms of action rely on binding $A \beta$ and do not need effector function to clear $A \beta$. However, the first-in-class $m A b s$ against $A \beta$ are full $\operatorname{IgG}_{1} s$ that strongly mediate pro-inflammatory effector functions. But, the Fc-domain of the antibodies can mediate toxicity since $A \beta$ is also deposited in cerebral vasculature forming vascular plaques. In particular ApoE4 (a hereditary risk factor for $\mathrm{AD}$ ) carriers reveal vascular amyloid plaques [35]. Anti-A $\beta$ antibodies capable to induce the complement system can lead to the formation of membrane attack complexes and thereby microbleedings i.e. microhemorrhages, vasogenic edema or if diagnosed with magnetic resonance imaging amyloid-related imaging abnormalities (ARIA) [36].

Conversely, many conflicting data exists about the mechanism of action of different epitope-specific antibodies and also about their blood-brain barrier passage (for review see [33]). Thus, one might assume that more than a single process takes place in passive $A \beta$ immunotherapy. In summary, it appears that clearing cerebral $A \beta$, quite irrespective from the mechanism of action, is needed for improvement in brain pathology, synaptic transmission and cognition in $\mathrm{AD}$ animal models given the well-known limitation of $\mathrm{AD}$ models.

The most advanced clinical candidates all recognize more or less linear epitopes on the $A \beta$ peptide. Bapineuzumab (3D6) recognizes the linear $\mathrm{N}$-terminus of $A \beta$ and binds all forms of $\mathrm{A} \beta$ (e.g. prefibrillar aggregates and plaques) $[37,38]$. Recently binding of 3D6 to A $\beta$-oligomers from an AD animal model was shown, but could not be confirmed for CSF from AD patients [39]. Bapineuzumab is believed to mainly clear $\mathrm{A} \beta$ by passing the blood-brain barrier and subsequent microglial engulfment, sequestration but also peripheral sink. In Summer 2012, the sponsors of the Bapineuzumab Phase III clinical trial reported disappointing results and the discontinuation of all but one subcutaneous clinical trial [40]. In detail, the studies involving ApoE4 carriers and non-carriers failed to show any significant benefit on cognition or functional performance, even though positive effects on the secondary 
Table 1 Passive immunotherapy for AD in clinical Phases, adopted from [33], anti-Aß antibodies in clinical Phases I - III

\begin{tabular}{|c|c|}
\hline $\mathrm{mAb}$ & Specific for \\
\hline $\begin{array}{l}\text { Bapineuzumab, humanized } \\
\text { 3D6 }\end{array}$ & N-terminus (aa 1-5) \\
\hline $\begin{array}{l}\text { Solanezumab, humanized } \\
\text { m266 }\end{array}$ & $\begin{array}{l}\text { central (aa 16-24), accessible only on } \\
\text { soluble } A \beta\end{array}$ \\
\hline
\end{tabular}

$\begin{array}{ll}\begin{array}{l}\text { Gantenerumab, full human } \\ \text { mAb }\end{array} & \begin{array}{l}\text { N-terminal (aa 3-12) and C-terminu } \\ \text { (aa 18-27) }\end{array} \\ & \\ \text { IVIG containing polyclonal } & \text { most NAbs-A } 3 \text { bind central and C- } \\ \text { NAbs-A : Gammagard, } & \text { terminus as well as pathogenic } \\ \text { Octagam, New Gam, } & \text { conformations of A (focus on } \\ \text { Flebogamma } & \text { dimers) }\end{array}$

Crenezumab, humanized mMABT

BAN2401, humanized mAb158

GSK933776

AAB-003, Fc-engineered

Bapineuzumab

SAR228810, humanized mAb 13C3

BIIB037/BART, full human oligomeric and protofibrillar forms, (aa 13-14 appears relevant)

binds large-size $A \beta$ protofibrils $(>100 \mathrm{kDa})$

$\mathrm{N}$-terminus of $A B$

N-terminal (aa 1-5)

protofibrils, and low molecular weight $A B$

binds insoluble fibrillar human $A \beta$ conformational epitopes including
Clinical trials

Phase III: trials were halted after completion

of two trials demonstrated a failure to meet

primary outcome measures of cognition and activities of daily living

Phase III: ongoing as preventive trial in familial AD (DIAN). Trials failed to meet their primary endpoints in cognition and activities of daily living. A subsequent analysis of mild $A D$ patients pooled from both trials showed a significant effect on cognition.

Phase III: ongoing in prodromal AD patients (DIAN), amyloid reduction but also ARIAs were observed in Phase I.

Phase III (Gammagard): ongoing, (improved cerebral glucose metabolism and cognitive stabilization of $A D$ symptoms was shown in small clinical studies, too small for statistical evaluation)

Phase III (Plasmapheresis with infusion of 20\% albumin and Flebogamma): ongoing

Phase II (Octagam): cognition endpoints not met, but improved cerebral glucose metabolism

Phase II (NewGam): ongoing

Phase II: ongoing as long-term safety extension study.

Preventive trial in an extended family carrying a presenilin-1 mutation, which causes early onset AD planned for 2013.

Phase Il: ongoing

Phase I: two clinical trials for $A D$ are completed and one for macular degeneration is ongoing. Further development for macular degeneration is in Phase II.

Phase I: ongoing. Lower toxicity (ARIAs) compared to Bapineuzumab is expected. Continuation as open-label extension study

Phase I: ongoing

Phase l: ongoing in prodromal AD patients
References

[41-43]

[44-46]

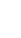
$\lg \mathrm{G}_{1}$

(aa, amino acid; $A \beta$, Amyloid- $\beta$; ApoE4, ApolipoproteinE4; ARIA, amyloid-related imaging abnormalities; DIAN, Dominantly Inherited Alzheimer Network; IVIG, Intravenous Immunoglobulin; $N A b s-A \beta$, natural occurring polyclonal Anti-A $\beta$ antibodies).

biomarker endpoints (cerebral amyloid burden and CSF phospho-tau) were found. ARIA, seizures and deaths occurred more frequently [41-43]. However, by subsequent pooling of non-carrier patients with very mild $\mathrm{AD}$ across the studies potential treatment benefits in disability assessment score were achieved, implying that an earlier treatment in the pathogenesis might be useful.

AAB-003/PF-05236812 is a humanized 3D6 (i. e. Bapineuzumab) with mutations in the Fc domain [56] to reduce effector functions and thereby ARIAs. Therefore, an improved clinical safety profile of AAB-003 compared to Bapineuzumab could be expected. Currently two clinical Phase I trials are ongoing to evaluate the safety and the tolerability of AAB-003.

Solanezumab (m266) recognizes a linear epitope in the centre of $A \beta$ and therefore does not bind any larger $A \beta$ aggregates [60]. Therefore, the only conceivable mechanisms of actions for Solanezumab are peripheral sink and sequestration. The $\mathrm{mAb}$ also failed some weeks later than Bapineuzumab in Phase III in two clinical trials to meet its primary cognitive and functional endpoints $[61,62]$. Surprisingly, in a secondary analysis a reduction 
in cognitive decline in very mild $\mathrm{AD}$ patients was observed after switching the cognition score, again implying that earlier treatment could be beneficial. There were no changes noted in biomarkers such as tau, phospho-tau, hippocampal volume, whole brain volume, or amyloid accumulation [44]. The sponsors are apparently not discouraged by the data and continue the clinical development of Solanezumab in an open-label extension study.

Gantenerumab (RO4909832 or R1450) is a fully human $\mathrm{mAb}$ that recognizes the N-terminal and the central region within $A \beta[47,48]$. The binding profile of the $\mathrm{mAb}$ was engineered by in vitro maturation on fibrillar $A \beta$, resulting in a mAb that binds $A \beta$ monomers and fibrils, conformed by $x$-ray diffraction. In addition, it was described, that Gantenerumab neutralizes $A \beta_{42}$ oligomers. These oligomers, however, were pre-treated with HFIP and diluted in Tris-buffer resulting in a mixture of LMWO and higher aggregates to our knowledge [28], therefore oligomer-specificity has yet not directly been shown. In a Phase I clinical trial, Gantenerumab reduced cerebral amyloid, but also ARIA were observed. The human $\mathrm{mAb}$ is currently in Phase III.

GSK933776 is a humanized mAb directed against the $\mathrm{N}$-terminus of $\mathrm{A} \beta$, believed as linear epitope [55]. The Fc domain of GSK933776 was mutated to reduce the risk for vasogenic edema. Development for AD was discontinued after Phase I in 2011.

The so-called second generation of anti- $\mathrm{A} \beta \mathrm{mAbs}$ is in development to target pathogenic $A \beta$ multimers rather than $\mathrm{A} \beta$ monomers or fibrils. However, as already mentioned the prefibrillar $\mathrm{A} \beta$-preparations are usually not well defined making it difficult to judge the recognized pathogenic species. Moreover, since binding studies for characterization are usually performed in an ELISA-like assay with the full IgG, it is not clear whether affinity or avidity was measured.

BAN2401 is the humanized mAb158 derived from mice immunized with protofibrils derived from the arctic mutation of $A \beta_{42}$. Arctic $A \beta$ is not able to fibrillize and thus remains prefibrillar [63]. BAN2401 was the first $\mathrm{mAb}$ believed to selectively bind, neutralize and eliminate protofibrils. Nevertheless, affinity for other aggregate species than protofibrils cannot be ruled out since the primary characterization of the here applied aggregates is based on SEC data revealing a peak at the exclusion limit of the used column. This peak might comprise a broad range of aggregates larger than $60 \mathrm{kDa}$. Their ELISA data give rise for an antibody, which is rather specific for prefibrillar and fibrillar $\mathrm{A} \beta$. BAN/mAb158 is being evaluated in clinical Phase II.

Crenezumab (MABT5102 or RG7412) was derived by immunization with modified $A \beta_{1-15}$ [52], containing a human $\mathrm{IgG}_{4}$ backbone to reduce effector function [64-66]. MABT5102A is supposed to target multiple conformational protofibrillar epitopes of $A \beta$, including oligomeric forms, while inhibiting aggregation and promoting disaggregation of $A \beta$ [67]. Though, having a closer look at the preparation of the $A \beta_{42}$ aggregates, this appears rather an empiric than a defined preparation. The only characterization method for the A $\beta$ preparation was SDS-PAGE and controls or head-to-head comparison with other mAbs were missing in the activity assays. A Phase I clinical trial proved safety, Phase II is ongoing.

SAR228810 was derived from 13C3 by immunization with polymerized synthetic $A \beta_{42}$ peptide while the degree of fibrillar $A \beta_{42}$ content was monitored by circular dichroism spectroscopy $[57,68]$. The immunogenic peptide was thereby rather well defined. $13 \mathrm{C} 3$ is therefore believed to recognize a conformational epitope of prefibrillar $\mathrm{A} \beta$ aggregates. The humanized $13 \mathrm{C} 3$ is in clinical Phase I evaluation.

BIIB037/BART is a novel fully human $\operatorname{IgG}_{1}$ and was generated using a reverse translational medicine approach screening endogenous anti- $\mathrm{A} \beta$ antibodies from an $\mathrm{AD}$ patient with an unusual stable clinical course [58]. BART apparently shows a high affinity/avidity for insoluble fibrillar $A \beta$ and a 100 -fold decreased affinity for $A \beta$ monomers. The applied $A \beta$-preparation for characterization of this antibody comprises a broad range of aggregates and the terminus fibrillar is not well defined. Thus, it is not surprising that BART reveals substantially identical affinity to monomeric and fibrillar $A \beta$ since it is specific for any $A \beta$-aggregate species [69]. In APP transgenic mice BART reduced amyloid burden while $A \beta$ plasma increase was not observed. Microglia appeared to play a pivotal role in clearing plaques [70]. A Clinical Phase I trial is currently ongoing.

$\mathrm{A} \beta_{20-42}$ globulomers, a condensed and hydrophobic oligomer in presence of $0.2 \%$ SDS, were used for immunization to develop the mAb A-887755 that is supposed to differentiate $A \beta$ globulomers from all other $A \beta$ species, especially monomers and fibrils [71,72]. But again, the characterization was based on SEC, WB, thus not allowing for a definition of the $A \beta$-aggregate species. Nevertheless, A-887755 has high affinity/avidity for immobilized $A \beta_{20-42}$ globulomers and detects endogenous $A \beta$ species but not in non-demented age-matched control patients nor in vascular $\mathrm{A} \beta$ deposits. A-887755 was characterized in preclinical studies and has yet not been advanced to the clinic.

To summarize, many different aggregation protocols have been applied to generate $A ß$-aggregates for immunization resulting in a broad range of applied $A ß$-species. Taking into account that the applied species have a transient nature, the fate after injection is not clear and thus the effective antigen as well not. Furthermore, the terms used for the definition of $A \beta$-aggregate species are still not coherent and hamper any comparison. 
Currently, there is a small chance of proving the clinical efficacy of anti-A $\beta$ mAbs in 'ordinary' clinical trials, since early diagnosis based on CSF and imaging biomarkers for a successful treatment with disease modifying drugs has still not been achieved. One - probably last - chance would be preventive trials in familial $\mathrm{AD}$ cases that were currently started with Crenezumab. Remarkably, efficacy will be tested in a five-year prevention trial in an extended Columbian family carrying an AD-related mutation, which causes early onset AD [73]. Moreover, the "Dominantly Inherited Alzheimer's Network", DIAN, will launch clinical trials with Solanezumab and Gantenerumab soon in large families with genetic mutations that make them susceptible to the disease [45].

\section{Naturally anti-A $\beta$ antibodies and IVIG treatment: is polyclonal the key?}

Polyclonal naturally occurring autoantibodies against $A \beta$ $(\mathrm{NAbs}-\mathrm{A} \beta)$ are found in serum of healthy persons and are reduced in AD patients [74-76]. Intravenous immunoglobulins, i.e. IVIGs, are commercially available as polyclonal Ig preparations purified from human plasma and are authority-approved for the treatment of immunosuppression, autoimmunity and a variety of other neurological conditions. IVIG contains NAbs-A $\beta$ and interestingly, regular IVIG treatment reduced the risk of developing AD by more than $40 \%$ in these patients [77].

Moreover, NAbs-A $\beta$ seem to inhibit the propensity of $A \beta$ to aggregate, thereby blocking its toxicity, and affected the clearance of $A \beta$, but NAbs-A $\beta$ did not readily clear senile plaques although early fleecy-like plaques were reduced. [78]. In epitope mapping, NAbs-A $\beta$ detected mainly the mid-/C-terminal epitope of $A \beta$, starting at the amino acid 28 . NAbs-A $\beta$ are believed to preferentially capture apparent dimers and trimers and interfere with oligomers $[79,80]$, which were prepared as described from Kayed et al. [24]. It is hypothesized that NAbs-A $\beta$ rather recognize a common conformational epitope than a distinct peptide sequence [81]. In active $A \beta$ immunization studies in AD patients, fibrillar $A \beta_{42}$ was used as an antigen, suggesting that $\mathrm{N}$-terminal epitopes of the $A \beta$ peptide were predominantly exposed and were available as binding sites. Accordingly, active immunization like AN-1792 generated primarily antibodies that recognized the N-terminus [82]. Likewise, $A \beta$ peptide is deposited in a fibrillar form in the plaques, and the $\mathrm{N}$-terminal part of the $\mathrm{A} \beta$ peptide is mostly available at the plaque surface. In contrast, NAbs-A $\beta$, mainly directed to the central and $\mathrm{C}$-terminal epitopes of $A \beta$, are less capable of binding the $N$-terminus of $A \beta$; thus NAbs-A $\beta$ do not clear plaques.

In different clinical pilot studies [76,83,84], IVIG affected plasma $A \beta$, improved cognition and the amount of Nabs- $A \beta$ in patient's serum increased dose-dependently with IVIG treatment. However, those trials did not have strong statistical significance. In a subsequent small Phase II study, IVIG exhibited a dose-dependent effect on brain atrophy [85] that was assumed to be correlated with improvement in clinical outcomes [86]. Preliminary data released in summer 2012 [49,50] showed a three-year stabilization of AD symptoms with IVIG, including no decline in cognition, memory, daily functioning and mood. The patient number involved is rather small: out of $16 \mathrm{pa}-$ tients who completed the open-label three-year follow-up, four patients receiving the most effective dose were principally unchanged from their cognitive baseline. A recently completed study using IVIGs from another manufacture has not met its primary endpoints in improving or stabilizing cognition [51]. Conversely to previous studies, no changes in plasma and CSF A $\beta$ could have been detected during the treatment. The only apparent benefit of the treatment was a significant improvement in cerebral glucose metabolism.

Several Phase II and III trials of IVIG in AD are currently ongoing. Meanwhile, the sponsors of the largest current trials are less optimistic to achieve endpoints in mild-to-moderate AD [87]. While IVIG could apparently demonstrate a positive signal in early $\mathrm{AD}$, the effects on cognition are unlikely to be statistically significant in more advanced AD. Possibly, the previous results from small cohorts included patients early in AD pathogenesis and are therefore not comparable with the studies from Bapineuzumab and Solanezumab. Finally, in geriatric patients the use of IVIG is often limited by renal insufficiency [88] and we would not have enough blood donors to supply all upcoming AD patients with IVIG [89] in case that Phase III trials give positive results.

\section{Conclusion}

To summarize, the reported and potentially relevant $A \beta-$ aggregates range from the smallest possible aggregate the dimer - up to particles with hundreds of $\mathrm{kDa}$. Furthermore, all of these reveal neuronal impairment in $\mathrm{AD}$ models. Including the many reported methods for $A \beta$ aggregate preparation one might question whether the whole spectrum of prefibrillar $A \beta$-aggregates is of relevance in $A D$ and that some $A \beta$-aggregative species might share conformational motifs exerting pathophysiological effects [90]. Possibly, the ongoing polymerization process promotes A $\beta$-related neurotoxicity [91] via many transient aggregate intermediates. In addition, most of the described $\mathrm{A} \beta$-aggregates are not covalently bound and reveal remarkable meta-stability, with the ability for reorganization within different aggregate equilibria $[11,17,28]$. It is conceivable that commonly used methods for $A \beta$ characterization provide only an isolated view of individual $A \beta$-species as opposed to the entire spectrum of $A \beta$ aggregates. This also has implications for immunization 
with $A \beta$-aggregates, since their fate after injection is entirely elusive owing to their transient nature.

Therefore it might be a long run to define a species as well as to pick out the corresponding antibody. There might be a conservative conformation shared by prefibrillar aggregates, which could be identified as promising target, however this is still elusive. We assume that explicitly hunting for conformation specific monoclonal antibodies is less promising than depleting whole $A \beta$ from the brain with a polyclonal approach unless the toxicity-mediating motif has been identified. Polyclonal IVIGs appear to recognize more than one species of $A \beta$, which would probably explain why patients treated with IVIGs for immunological indications have a reduced risk to develop AD.

From the regulatory point of view, the approval of a highly innovative active substance for the treatment for AD still remains a challenge. Although, biomarker strategies have been more and more taken into account, the current study designs for $\mathrm{AD}$ superficially address the silent pathogenesis of the disease. Hence, meta-analysis of current clinical trials confirms that preventive approaches might be the right tool to avoid the onset of AD. Furthermore the selection of a geriatric-friendly application form might play an important role with respect to a "total compliance". Therefore, it might be the more promising strategy to approach the whole spectrum of $A \beta$ aggregates rather than to focus on a distinct aggregative species by acute treatment, thus, to generally diminish $A \beta$ by means of a control-released immunotherapy suitable for a geriatric population. Possibly, IVIG or the translational medicine approach can support the hunt for the one toxic species of $A \beta$ as it seems that we have the key in our plasma, recognizing pathogenic proteins.

\section{Abbreviations}

aa: Amino acid; $A B$ : Amyloid-beta; $A D$ : Alzheimer's disease; $A ß O: A ß$ oligomers; ASPD: Amylospheroids; ADL: Alzheimer's disease; ADDLs: Alzheimer derived diffusible ligands; APP: Amyloid Precursor Protein; ApoE4: ApolipoproteinE4; ARIA: Amyloid-related imaging abnormalities; CSF: Cerebrospinal fluid; DIAN: Dominantly inherited alzheimer's network; ELISA: Enzyme linked immunosorbent assay; Fc: Fragment crystallizable; HFIP: Hexafluoroisopropanol; HMW: High molecular weight; Ig: Immunoglobulins; IVIG: Intravenous immunoglobulins; LMW: LoW molecular weight; NAbs-A 3 : Naturally occurring autoantibodies against $A \beta$; phospho-tau: Hyperphosphorylated tau; SDS-PAGE: Sodium dodecyl sulfate polyacrylamide gel electrophoresis; SEC: Size-exclusion chromatography Tris: Tris(hydroxymethyl)aminomethane; WB: Western blotting.
\end{abstract}

\section{Competing interests}

JM and KS are former employees of Boehringer Ingelheim Pharma, CM is a former employee of Ratiopharm $\mathrm{GmbH}$. KS supported and holds a patent related to this field.

\section{Authors' contribution}

JM supported with novel data on A 3 conformation and aggregation, CM supported with insight from regulatory affairs and KS supported with insight on $A \beta$ immunotherapy und neuroimmunology. All authors drafted the manuscript. All authors read and approved the final manuscript.

\section{Acknowledgement}

The authors thank Martin Scudamore for language editing and help with the manuscript.

Received: 30 November 2012 Accepted: 1 May 2013

Published: 11 May 2013

\section{References}

1. World Alzheimer Report; 2009. http://www.alz.co.uk/research/world-report.

2. Wyss-Coray T: Inflammation in Alzheimer disease: driving force, bystander or beneficial response? Nat Med 2006, 12:1005-1015.

3. Selkoe DJ: Alzheimer's Disease: Genes, Proteins, and Therapy. Physiol Rev 2001, 81:741-766.

4. Atwood CS, Martins RN, Smith MA, Perry G: Senile plaque composition and posttranslational modification of amyloid-beta peptide and associated proteins. Peptides 2002, 23:1343-1350.

5. Hardy J, Allsop D: Amyloid deposition as the central event in the aetiology of Alzheimer's disease. Trends Pharmacol Sci 1991, 12:383-388.

6. Hardy J, Selkoe DJ: The amyloid hypothesis of Alzheimer's disease: progress and problems on the road to therapeutics. Science 2002, 297:353-356.

7. Verdile G, Fuller S, Atwood CS, Laws SM, Gandy SE, Martins RN: The role of beta amyloid in Alzheimer's disease: still a cause of everything or the only one who got caught? Pharmacol Res 2004, 50:397-409.

8. Bitan G, Vollers SS, Teplow DB: Elucidation of primary structure elements controlling early amyloid beta-protein oligomerization. J Biol Chem 2003, 278:34882-34889.

9. Kuo YM, Emmerling MR, Vigo-Pelfrey C, Kasunic TC, Kirkpatrick JB, Murdoch $\mathrm{GH}$, Ball MJ, Roher AE: Water-soluble Abeta (N-40, N-42) oligomers in normal and Alzheimer disease brains. J Biol Chem 1996, 271:4077-4081.

10. Lambert MP, Barlow AK, Chromy BA, Edwards C, Freed R, Liosatos M, Morgan TE, Rozovsky I, Trommer B, Viola KL, Wals P, Zhang C, Finch CE, Krafft GA, Klein WL: Diffusible, nonfibrillar ligands derived from Abeta1-42 are potent central nervous system neurotoxins. Proc Natl Acad Sci USA 1998, 95:6448-6453.

11. Kuperstein I, Broersen K, Benilova I, Rozenski J, Jonckheere W, Debulpaep M, Vandersteen A, Segers-Nolten I, Van Der Werf K, Subramaniam V, Braeken D, Callewaert G, Bartic C, D'Hooge R, Martins IC, Rousseau F, Schymkowitz J, De Strooper B: Neurotoxicity of Alzheimer's disease Abeta peptides is induced by small changes in the Abeta42 to Abeta40 ratio. EMBO J 2010, 29:3408-3420.

12. Katzman R: Alzheimer's disease. N Engl J Med 1986, 314:964-973.

13. Terry RD, Masliah E, Salmon DP, Butters N, DeTeresa R, Hill R, Hansen LA, Katzman R: Physical basis of cognitive alterations in Alzheimer's disease: synapse loss is the major correlate of cognitive impairment. Ann Neurol 1991, 30:572-580.

14. Walsh DM, Klyubin I, Fadeeva JV, Cullen WK, Anwyl R, Wolfe MS, Rowan MJ, Selkoe DJ: Naturally secreted oligomers of amyloid beta protein potently inhibit hippocampal long-term potentiation in vivo. Nature 2002, 416:535-539.

15. Walsh DM, Selkoe DJ: A beta oligomers - a decade of discovery. J Neurochem 2007, 101:1172-1184.

16. Benilova I, Karran E, De Strooper B: The toxic Abeta oligomer and Alzheimer's disease: an emperor in need of clothes. Nat Neurosci 2012, 15:349-357.

17. O'Nuallain B, Freir DB, Nicoll AJ, Risse E, Ferguson N, Herron CE, Collinge J, Walsh DM: Amyloid beta-protein dimers rapidly form stable synaptotoxic protofibrils. J Neurosci 2010, 30:14411-14419.

18. Shankar GM, Li S, Mehta TH, Garcia-Munoz A, Shepardson NE, Smith I, Brett FM, Farrell MA, Rowan MJ, Lemere CA, Regan CM, Walsh DM, Sabatini BL, Selkoe DJ: Amyloid-beta protein dimers isolated directly from Alzheimer's brains impair synaptic plasticity and memory. Nat Med 2008, 14:837-842.

19. Walsh DM, Townsend M, Podlisny MB, Shankar GM, Fadeeva JV, El Agnaf O, Hartley DM, Selkoe DJ: Certain inhibitors of synthetic amyloid betapeptide (Abeta) fibrillogenesis block oligomerization of natural Abeta and thereby rescue long-term potentiation. J Neurosci 2005, 25:2455-2462.

20. Ahmed M, Davis J, Aucoin D, Sato T, Ahuja S, Aimoto S, Elliott JI, Van Nostrand WE, Smith SO: Structural conversion of neurotoxic amyloid-beta (1-42) oligomers to fibrils. Nat Struct Mol Biol 2010, 17:561-567. 
21. Lesne S, Koh MT, Kotilinek L, Kayed R, Glabe CG, Yang A, Gallagher M, Ashe $\mathrm{KH}$ : A specific amyloid-beta protein assembly in the brain impairs memory. Nature 2006, 440:352-357.

22. Reed MN, Hofmeister JJ, Jungbauer L, Welzel AT, Yu C, Sherman MA, Lesne S, LaDu MJ, Walsh DM, Ashe KH, Cleary JP: Cognitive effects of cell-derived and synthetically derived Abeta oligomers. Neurobiol Aging 2011, 32:1784-1794

23. Barghorn S, Nimmrich V, Striebinger A, Krantz C, Keller P, Janson B, Bahr M Schmidt M, Bitner RS, Harlan J, Barlow E, Ebert U, Hillen H: Globular amyloid beta-peptide oligomer - a homogenous and stable neuropathological protein in Alzheimer's disease. J Neurochem 2005, 95:834-847.

24. Kayed R, Head E, Thompson JL, McIntire TM, Milton SC, Cotman CW, Glabe CG: Common structure of soluble amyloid oligomers implies common mechanism of pathogenesis. Science 2003, 300:486-489.

25. Walsh DM, Hartley DM, Kusumoto Y, Fezoui Y, Condron MM, Lomakin A Benedek GB, Selkoe DJ, Teplow DB: Amyloid beta-protein fibrillogenesis. Structure and biological activity of protofibrillar intermediates. J Biol Chem 1999, 274:25945-25952.

26. Hoshi M, Sato M, Matsumoto S, Noguchi A, Yasutake K, Yoshida N, Sato K: Spherical aggregates of beta-amyloid (amylospheroid) show high neurotoxicity and activate tau protein kinase I/glycogen synthase kinase-3beta. Proc Natl Acad Sci USA 2003, 100:6370-6375.

27. Kirschner DA, Abraham C, Selkoe DJ: X-ray diffraction from intraneuronal paired helical filaments and extraneuronal amyloid fibers in Alzheimer disease indicates cross-beta conformation. Proc Natl Acad Sci USA 1986, 83:503-507.

28. Moreth J, Kroker KS, Schwanzar D, Schnack C, Von Arnim CAF, Hengerer B, Rosenbrock H, Kussmaul L: Globular and Protofibrillar A $\beta$ Aggregates Impair Neurotransmission by Different Mechanisms. Biochemistry 2013 52:1466-1476.

29. Roychaudhuri R, Yang M, Hoshi MM, Teplow DB: Amyloid beta-protein assembly and Alzheimer disease. J Biol Chem 2009, 284:4749-4753.

30. Rahimi F, Shanmugam A, Bitan G: Structure-function relationships of prefibrillar protein assemblies in Alzheimer's disease and related disorders. Curr Alzheimer Res 2008, 5:319-341.

31. Orgogozo J-M, Gilman S, Dartigues J-F, Laurent B, Puel M, Kirby LC, Jouanny P, Dubois B, Eisner L, Flitman S, Michel BF, Boada M, Frank A, Hock C: Subacute meningoencephalitis in a subset of patients with $A D$ after Aß42 immunization. Neurology 2003, 61:46-54.

32. Holmes C, Boche D, Wilkinson D, Yadegarfar G, Hopkins V, Bayer A, Jones RW, Bullock R, Love S, Neal JW, Zotova E, Nicoll JA: Long-term effects of Abeta42 immunisation in Alzheimer's disease: follow-up of a randomised, placebo-controlled phase I trial. Lancet 2008, 372:216-223

33. Mavoungou C, Schindowski K: Immunotherapy with anti-Amyloid-beta antibodies in Alzheimer's disease: A critical review on the molecules in the pipelines with regulatory considerations. In Frontiers in Clinical Drug Research - Alzheimer Disorders. Edited by Ur Rahman A. Bentham Science Publishers: 2013, in press.

34. Fu HJ, Liu B, Frost JL, Lemere CA: Amyloid-beta immunotherapy for Alzheimer's disease. CNS Neurol Disord Drug Targets 2010, 9:197-206.

35. Greenberg SM, William Rebeck G, Vonsattel JPG, Gomez-Isla T, Hyman BT: Apolipoprotein E ?4 and cerebral hemorrhage associated with amyloid angiopathy. Ann Neurol 1995, 38:254-259.

36. Frisoni GB: ARIA from off-key operas? Lancet Neurol 2012, 11:207-208.

37. Schenk DB: Passive immunization treatment of Alzheimer's disease (US Patent); 2004

38. Schenk DB, Bard F, Yednock T: Humanized and chimeric N-terminal amyloid beta-antibodies (US Patent); 2004.

39. Yang T, Hong S, O'Malley T, Sperling RA, Walsh DM, Selkoe DJ: New ELISAs with high specificity for soluble oligomers of amyloid $B$-protein detect natural $A ß$ oligomers in human brain but not CSF. Alzheimers Dement 2013, 9:99-112.

40. Johnson \& Johnson Announces Discontinuation Of Phase 3 Development of Bapineuzumab Intravenous (IV) In Mild-To-Moderate Alzheimer's Disease. http://www.jnj.com/connect/news/product/johnson-and-johnsonannounces-discontinuation-of-phase-3-development-of-bapineuzumabintravenous-iv-in-mild-to-moderate-alzheimers-disease.

41. Salloway S, Sperling R, Honig L, Porsteinsson A, Sabbagh M, Liu E, Yuen E, Lull J, Miloslavsky M, Reichert M, Ketter N, Grundman M, Black R, Brashear HR: A randomized, double-blind, placebo-controlled clinical trial of intravenous bapineuzumab in patients with Alzheimer's disease who are apolipoprotein E e4 non-carriers [abstract]. Eur J Neurol 2012, 19:SC312.

42. Sperling R, Salloway S, Raskind M, Ferris S, Liu E, Yuen E, Lu Y, Wang D, Nejadnik B, Guenzler V, Grundman M, Black R, Brashear HR: A randomized, double-blind, placebo-controlled clinical trial of intravenous bapineuzumab in patients with Alzheimer's disease who are apolipoprotein E e4 carriers [abstract]. Eur J Neurol 2012, 19, SC3012.

43. Sperling R, Salloway S, Brooks DJ, Tampieri D, Barakos J, Fox NC, Raskind M, Sabbagh M, Honig LS, Porsteinsson AP, Lieberburg I, Arrighi HM, Morris KA, Lu Y, Liu E, Gregg KM, Brashear HR, Kinney GG, Black R, Grundman M: Amyloid-related imaging abnormalities in patients with Alzheimer's disease treated with bapineuzumab: a retrospective analysis. Lancet Neurol 2012, 11:241-249.

44. Indipendent analysis of Solanezumab provides evidence that compound may remove Amyloid from brain in Alzheimer's Disease; 2012. http://www.ctad.fr/ 07-download/Congres2012/PressRelease/Sola-Release_290ct2012.pdf.

45. Alzheimer's Prevention Study in Genetically Defined High-Risk Patients Includes Roche, Lilly Drugs. http://www.genomeweb.com/clinical-genomics/alzheimersprevention-study-genetically-defined-high-risk-patients-includes-roch

46. Farlow M, Arnold SE, Van Dyck CH, Aisen PS, Snider BJ, Porsteinsson AP, Friedrich S, Dean RA, Gonzales C, Sethuraman G: Safety and biomarker effects of solanezumab in patients with Alzheimer's disease. Alzheimers Dement 2012, 8:261-271.

47. Bohrmann B, Baumann K, Benz J, Gerber F, Huber W, Knoflach F, Messer J, Oroszlan K, Rauchenberger R, Richter WF: Gantenerumab: a novel human anti-Aß antibody demonstrates sustained cerebral amyloid- $ß$ binding and elicits cell-mediated removal of human amyloid- $ß$. J Alzheimers Dis 2012, 28:49-69.

48. Ostrowitzki S: DDTL, et?al.: Mechanism of amyloid removal in patients with alzheimer disease treated with gantenerumab. Arch Neurol 2012, 69:198-207.

49. Alzheimer's Treatment Study Reports Three Years with No Decline in Memory and Function at AAIC 2012; 2012. http://www.alz.org/aaic/releases/ tues 1030amct_ivig_trial.asp.

50. Mullane K, Williams M: Alzheimer's Therapeutics: Continued clinical failures question the validity of the amyloid hypothesis-but what lies beyond? Biochem Pharmacol 2012, 85:289-305.

51. Dodel R, Rominger A, Bartenstein P, Barkhof F, Blennow K, Förster S, Winter Y, Bach J-P, Popp J, Alferink J, Wiltfang J, Buerger K, Otto M, Antuono P, Jacoby M, Richter R, Stevens J, Melamed I, Goldstein J, Haag S, Wietek S, Farlow M, Jessen F: Intravenous immunoglobulin for treatment of mild-to -moderate Alzheimer's disease: a phase 2, randomised, double-blind, placebo-controlled, dose-finding trial. Lancet Neurol 2013, 12:233-243.

52. Muhs A, Hickman DT, Pihlgren M, Chuard N, Giriens V, Meerschman C, Van Der Auwera I, Van Leuven F, Sugawara M, Weingertner MC: Liposomal vaccines with conformation-specific amyloid peptide antigens define immune response and efficacy in APP transgenic mice. Proc Natl Acad Sci 2007, 104:9810.

53. Barcelona: Antibody to Sweep Up Aß Protofibrils in Human Brain. http://www. alzforum.org/new/detail.asp?id=2757.

54. Eisai announces the start of the first clinical study of BAN2401, a novel monoclonal antibody targeting the neurotoxic protofibrils believed to cause Alzheimer's disease. http://www.eisai.com/news/enews201044pdf.pdf

55. A randomised, single-blind, placebo-controlled study to investigate the safety, tolerability, immunogenicity, pharmacokinetics and pharmacodynamics of intravenous infusion of GSK933776 in patients with Alzheimer's disease. http:// www.gsk-clinicalstudyregister.com/result_comp_list.jsp?phase= All\&studyType=All\&population=All\&marketing=No\&compound=GSK933776.

56. Black R, Ekman L, Lieberburg I, Grundman M, Callaway J, Gregg K, Jacobsen J, Gill D, Tchistiakova L, Widom A: Immunotherapy regimes dependent on ApoE status (US Patent); 2009

57. Schupf N, Tang MX, Fukuyama H, Manly J, Andrews H, Mehta P, Ravetch J, Mayeux R: Peripheral Aß subspecies as risk biomarkers of Alzheimer's disease. Proc Natl Acad Sci 2008, 105:14052.

58. Dunstan R, Bussiere T, Rhodes K, Engber T, Maier M, Weinreb P, Grimm J, Nitsch R, Arustu M, Qian F, Li M: Molecular characterization and preclinical efficacy [abstract]. Alzheimer's \& dementia : the journal of the Alzheimer's Association 2011, 7:\$457.

59. Neurimmune Therapeutics Announces Advancement of Alzheimer's Program into Preclinical Development. http://www.neurimmune.com/index.php? section $=$ news\&cmd=details\&newsid $=7$. 
60. Holtzman DM, DeMattos R, Bales KR, Paul SM, Tsurushita N, Vasquez M: Humanized antibodies that sequester abeta peptide (US Patent); 2007.

61. Lilly Announces Detailed Results of the Phase 3 Solanezumab EXPEDITION Studies Following a Presentation of the Independent Analyses by the Alzheimer's Disease Cooperative Study (ADCS). http://newsroom.lilly.com/ releasedetail.cfm?ReleaselD $=702211$

62. Eli Lilly and Company Announces Top-Line Results on Solanezumab Phase 3 Clinical Trials in Patients with Alzheimer's Disease. http://newsroom.lilly.com/ releasedetail.cfm?ReleaselD $=702211$.

63. Englund H, Sehlin D, Johansson A-S, Nilsson LNG, Gellerfors P, Paulie S, Lannfelt L, Pettersson FE: Sensitive ELISA detection of amyloid- $\beta$ protofibrils in biological samples. J Neurochem 2007, 103:334-345.

64. Poduslo JF, Gilles EJ, Ramakrishnan M, Howell KG, Wengenack TM, Curran $G L$, Kandimalla KK: HH Domain of Alzheimer's Disease A $\beta$ Provides Structural Basis for Neuronal Binding in PC12 and Mouse Cortical/ Hippocampal Neurons. PLoS One 2010, 5:e8813.

65. Van der Zee JS, Van Swieten P, Aalberse RC: Inhibition of complement activation by IgG4 antibodies. Clin Exp Immunol 1986, 64:415.

66. Bruhns $P$, lannascoli B, England P, Mancardi DA, Fernandez N, Jorieux S, Daëron M: Specificity and affinity of human Fcy receptors and their polymorphic variants for human IgG subclasses. Blood 2009, 113:3716-3725.

67. Adolfsson O, Pihlgren M, Toni N, Varisco Y, Buccarello AL, Antoniello K, Lohmann S, Piorkowska K, Gafner V, Atwal JK, Maloney J, Chen M, Goginen A, Weimer RM, Mortensen DL, Friesenhahn M, Ho C, Paul R, Pfeifer A, Muhs A, Watts RJ: An Effector-Reduced Anti- $\beta$-Amyloid ( $A \beta$ ) Antibody with Unique $A \beta$ Binding Properties Promotes Neuroprotection and Glial Engulfment of $A \beta$. J Neurosci 2012, 32:9677-9689.

68. Ravetch J, Fukuyama H: Antibodies specific for the Protofibrilar Form of BetaAmyloid Protein (US Patent); 2009.

69. Esslinger C, Grimm J, Hock C, Knobloch M: Nitsch R. Method of Providing Disease-Specific Binding Molecules and Targets (US Patent): Tissot K; 2008.

70. Dunstan R, Bussiere T, Engber T, Weinreb P, Maier M, Grimm J, Rhodes K, Arastu M, Li M, Zhang X: The role of brain macrophages on the clearance of amyloid plaques following the treatment of Tc2576 with BIIB037 [abstract]. Alzheimer's \& dementia: the journal of the Alzheimer's Association 2011, 7:S700

71. Hillen H, Barghorn S, Striebinger A, Labkovsky B, Muller R, Nimmrich V, Nolte MW, Perez-Cruz C, Van der Auwera I, Van Leuven F, Van Gaalen M, Bespalov AY, Schoemaker H, Sullivan JP, Ebert U: Generation and therapeutic efficacy of highly oligomer-specific beta-amyloid antibodies. J Neurosci 2010, 30:10369-10379.

72. Relo A, Barghorn S, Ebert U, Hillen H, Gross G, Schoemaker H, Bespalov A Restoration of home cage activity in $\mathrm{Tg} 2576$ mice by immunotherapy with the Ab-oligomer selective antibody A-887755. Alzheimer's \& dementia: the journal of the Alzheimer's Association 2011, 7:S772.

73. New Drug Trial Seeks to Stop Alzheimer's Before It Starts. http://www.nytimes com/2012/05/16/health/research/prevention-is-goal-of-alzheimers-drug-trial. $\mathrm{html}$

74. Du Y, Dodel R: Human beta-amyloid antibody and use thereof for treatment of alzheimer's disease (US Patent); 2001.

75. Weksler ME, Relkin N, Turkenich R, LaRusse S, Zhou L, Szabo P: Patients with Alzheimer disease have lower levels of serum anti-amyloid peptide antibodies than healthy elderly individuals. Exp Gerontol 2002, 37:943-948.

76. Dodel RC, Du Y, Depboylu C, Hampel H, Frolich L, Haag A, Hemmeter U, Paulsen S, Teipel SJ, Brettschneider S, Spottke A, Nolker C, Moller HJ, Wei X, Farlow M, Sommer N, Oertel WH: Intravenous immunoglobulins containing antibodies against beta-amyloid for the treatment of Alzheimer's disease. J Neurol Neurosurg Psychiatry 2004, 75:1472-1474.

77. Fillit H, Hess G, Hill J, Bonnet P, Toso C: IV immunoglobulin is associated with a reduced risk of Alzheimer disease and related disorders. Neurology 2009, 73:180-185.

78. Weksler ME: The immunotherapy of Alzheimer's disease. Immun Ageing 2004, 1:2

79. Britschgi M, Olin CE, Johns HT, Takeda-Uchimura Y, LeMieux MC, Rufibach K, Rajadas J, Zhang H, Tomooka B, Robinson WH, Clark CM, Fagan AM, Galasko DR, Holtzman DM, Jutel M, Kaye JA, Lemere CA, Leszek J, Li G, Peskind ER, Quinn JF, Yesavage JA, Ghiso JA, Wyss-Coray T: Neuroprotective natural antibodies to assemblies of amyloidogenic peptides decrease with normal aging and advancing Alzheimer's disease. Proc Natl Acad Sci USA 2009, 106:12145-12150.
80. Mengel D, Roskam S, Neff F, Balakrishnan K, Deuster O, Gold M, Oertel WH, Bacher M, Bach J-P, Dodel R: Naturally occurring autoantibodies interfere with [beta]-amyloid metabolism and improve cognition in a transgenic mouse model of Alzheimer/'s disease $24 \mathrm{~h}$ after single treatment. Transl Psychiatry 2013, 3:233-243.

81. Dodel R, Balakrishnan K, Keyvani K, Deuster O, Neff F, Andrei-Selmer LC, Roskam S, Stuer C, Al-Abed Y, Noelker C, Balzer-Geldsetzer M, Oertel W, Du $Y$, Bacher M: Naturally occurring autoantibodies against beta-amyloid: investigating their role in transgenic animal and in vitro models of Alzheimer's disease. J Neurosci 2011, 31:5847-5854.

82. McLaurin J, Cecal R, Kierstead ME, Tian X, Phinney AL, Manea M, French JE, Lambermon MH, Darabie AA, Brown ME, Janus C, Chishti MA, Horne P, Westaway D, Fraser PE, Mount HT, Przybylski M, St George-Hyslop P: Therapeutically effective antibodies against amyloid-beta peptide target amyloid-beta residues 4-10 and inhibit cytotoxicity and fibrillogenesis. Nat Med 2002, 8:1263-1269.

83. Relkin NR, Szabo P, Adamiak B, Burgut T, Monthe C, Lent RW, Younkin S, Younkin L, Schiff R, Weksler ME: 8-Month study of intravenous immunoglobulin for treatment of mild Alzheimer disease. Neurobio/ Aging 2009, 30:1728-1736.

84. Rovira MB, Núñez L, Lafuente A, Hernandez I, Buendia M, Tarraga L, Roca I, Cuberas G, Torres M, Páez A: Peripheral amyloid-beta mobilization with the intravenous immunoglobulin Flebogamma $\mathrm{DIF}^{\oplus}$ in Alzheimer's disease patients. Alzheimers Dement 2011, 7:S456-S457.

85. Evans J: IVIG Reduced Brain Atrophy in Alzheimer's. Clinical Psychiatry News 2010, 38:12.

86. Comments on Paper and Primary News: Norman Relkin and Paul Szabo. http://www.alzforum.org/pap/annotation.asp?powlD=116328.

87. Kambhampaty A: Baxter's Gammagard unlikely to be successful in mild-to -moderate Alzheimer's, Financial Times; 2013. http://www.ft.com/intl/cms/s/2/ f5b1bb56-64c6-11e2-ac53-00144feab49a.htm|\#axzz2Pd1gYpU7.

88. Siegel J: IVIG medication safety: a stepwise guide to product selection and use. Pharm Pract News 2010, 1-8.

89. Hofbauer L, Bruckschwaiger L, Butterweck HA, Teschner W: Affinity Chromatography for Purification of lg $G$ from Human Plasma. http://cdn. intechopen.com/pdfs/33051/InTechAffinity_chromatography_for_purification_of_igg_from_human_plasma.pdf.

90. Broersen K, Rousseau F, Schymkowitz J: The culprit behind amyloid beta peptide related neurotoxicity in Alzheimer's disease: oligomer size or conformation? Alzheimers Res Ther 2010, 2:12.

91. Jan A, Adolfsson O, Allaman I, Buccarello AL, Magistretti PJ, Pfeifer A, Muhs A, Lashuel HA: Abeta42 neurotoxicity is mediated by ongoing nucleated polymerization process rather than by discrete Abeta42 species. J Biol Chem 2011, 286:8585-8596.

doi:10.1186/1742-4933-10-18

Cite this article as: Moreth et al:: Passive anti-amyloid immunotherapy in Alzheimer's disease: What are the most promising targets?. Immunity \& Ageing 2013 10:18

\section{Submit your next manuscript to BioMed Central and take full advantage of:}

- Convenient online submission

- Thorough peer review

- No space constraints or color figure charges

- Immediate publication on acceptance

- Inclusion in PubMed, CAS, Scopus and Google Scholar

- Research which is freely available for redistribution 